\title{
Sediment vs Topographic Roughness: Antropogenic Effects on Acoustic Seabed Classification
}

Ruggero Maria CAPPERUCCI

MARUM, Center for Marine Environmental Sciences, University of Bremen, Leobener Str.

D-28359 Bremen

Department of Earth and Ocean Sciences, University of Waikato, Private Bag 3105, Hamilton, New

Zealand

Marine Research Department, Senckenberg am Meer, Südstrand 40, 26382 Wilhelmshaven, Germany

Alexander BARTHOLOMÄ

Marine Research Department, Senckenberg am Meer, Südstrand 40, 26382 Wilhelmshaven, Germany

Topic: H Geophysics of the marine environment

\section{INTRODUCTION}

In recent years, environmental case studies of highly developed marine areas have become more relevant [Winter and Bartholomä, 2006; van der Veen and Hulscher, 2008]: for monitoring both the short- and long-term human impact on bio- and geo-sphere; for modelling the effects of such increasing pressure on ecosystem; as a key tool for environmental and socio-economic policy and management.

Among the different marine domains, coastal areas are the most accessible ones and the most difficult to be studied in detail, due to the complexity of natural and anthropic processes in action [OSPAR, 2008]. As a consequence, there is an increased demand for reliable high-resolution mapping tools, less dependent on expertise interpretation, and therefore more objective [Cutter, 2003].

In this scenario, the combination of acoustic, sedimentological and biological data is becoming the main approach for seabed habitat mapping studies [Brown, 2011]. Nevertheless, some specific aspects need further investigations: firstly, the analysis of acoustic data is still largely dependent on human expertise [Cutter, 2003]; secondly, repeated sampling technique is a standard procedure for biological studies but not a common practice for sedimentary research; and lastly, the ground-truthing process by means of sediment samples assumes that the point-based information can be consistently extended to the near vicinity of the sampling station. Besides, the positioning error/uncertainty is often not even mentioned as a key factor for assessing the reliability of the final seabed classification. The latter assumptions have to be proved for extremely heterogeneous environments, where anthropogenic impact increases significantly the disturbance (and, hence, the variability) of ecosystems.

In our study site of the Jade channel in the German Bight (southern North Sea) hydrodynamic conditions, topography, sediments and bio-communities are tremendously influenced by multiple human activities. Fishing and mussel farms are present [Herlyn and Millat, 2000]; the navigation channel is constantly monitored and dredged by the local harbour authority (Wasser- und Schiffahrtsamft Wilhelmshaven - WSA); moreover, a new container terminal (J ade-Weser Port, http://www.jadeweserport.de/) is under construction since 2008, with massive land reclamation, dredging and dumping operations. The Jade channel area represents, then, a unique site where to test the reliability of acoustic ground discrimination systems (AGDS) in a cumulative disturbed area.

The present study aims to address the following research questions:

1) What is the variability of repeated sediment samples in a highly heterogeneous environment?

2) How do the positioning error/uncertainty of sediment samples affect the ground-truthing process?

3) What drives the seabed classification in the different acoustic systems? 


\section{STUDY AREA AND METHODS}

The J ade channel connects the J ade Bay with the German Bight (southern North Sea), being part of a wide tidal flat system that includes the Weser estuary (Figure 1).

The northern end (Outer J ade) is a mesotidal environment (sensu Hayes, 1975), with semi-diurnal tides ranging between 2.3 and $2.8 \mathrm{~m}$, whereas the southern part (Inner Jade) is a macrotidal environment, with the tidal gauge reaching $3.9 \mathrm{~m}$ in Wilhelmshaven.

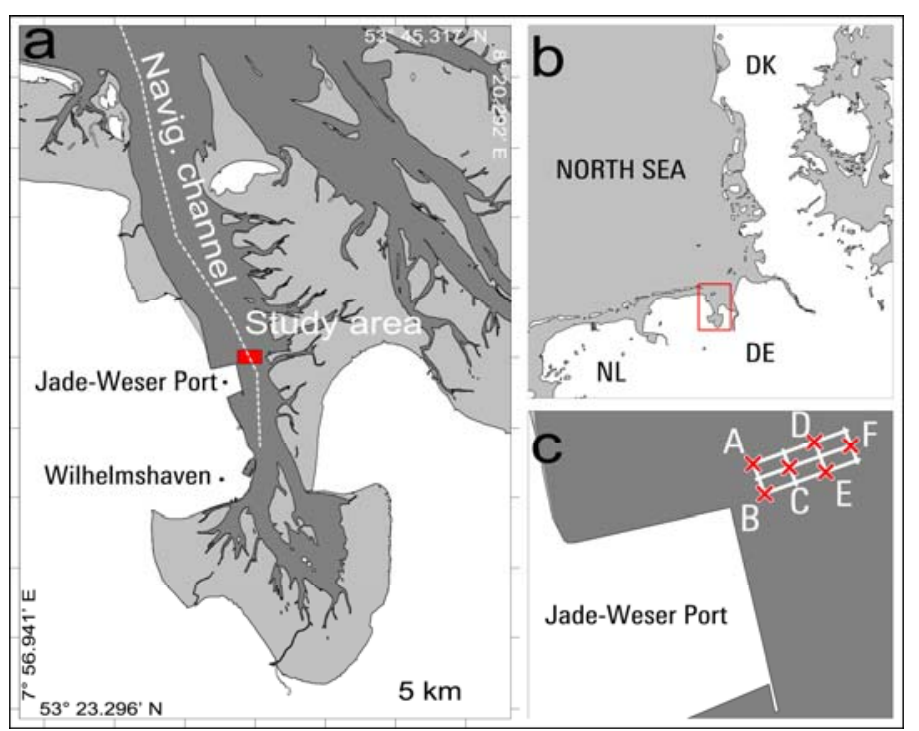

Figure 1 a) The Jade region, with the Jade-Weser Port and, in red, the study area. b) Location map of the Jade system. c) close up un the research site; white lines: main acoustic transects, red crosses: sampling stations
The sediment distribution shows a general decrease of the grain-size towards the high-tide line, with the finest sediments being located in the south-eastern part of the bay; the Inner J ade is characterized by the presence of fine sand; fine to medium sand occurs in the Outer J ade area [Kahlfeld and Schüttrumpf 2006]. Bedforms are commonly observed along the tidal inlet.

The research area covers approximately $0.8 \mathrm{~km}^{2}$ in the Jade Channel, north-east of the Jade-Weser Port, partially within the old navigation channel. The water depth ranges between 14 and $26 \mathrm{~m}$.

Acoustic data were collected aboard the R/V Senckenberg using a Reson Seabat $8125^{\mathrm{TM}}$ multibeam echosounder (MBES, $455 \mathrm{kHz}$ ), a dual-frequency Benthos $1624^{\mathrm{TM}}$ side-scan sonar (SSS, 110-390

$\mathrm{kHz}$ ) and a QTC $5.5^{\mathrm{TM}}$ system mounted on a Furuno FCV $1000^{\mathrm{TM}}$ single-beam echosounder (SBES, 200 $\mathrm{kHz}$ ). All devices were deployed simultaneously along 7 main transects ( 3 approximately east-west and 4 approximately north-south oriented). Additional lines were collected for a complete MBES coverage and a denser SBES grid. A DGPS system with LRK correction was used for positioning. 6 stations were sampled ( 4 replications each) using a Shipek grab.

\section{Data processing}

MBES bathymetric data were processed using QINSY ${ }^{T M}$ and a final $0.5 \times 0.5 \mathrm{~m}$ grid was computed. DTM generation and seabed features mapping was done under Global Mapper ${ }^{T M}$ v13. A set of QTC $^{T M}$ software was used for acoustic seafloor classification: QTC IMPACT ${ }^{\text {TM }}$ for SBES data, QTC SIDEVIEW ${ }^{\text {TM }}$ for SSS data, QTC SWATHVIEW ${ }^{T M}$ for MBES data, and QTC CLAMS ${ }^{T M}$ for visualizing and editing classified data.

QTC IMPACT ${ }^{\mathrm{TM}}$ is based on a statistical analysis of the echo-trace shape, whereas QTC SIDEVIEW ${ }^{T M}$ and QTC SWATHVIEW ${ }^{\mathrm{TM}}$ use statistical properties of backscatter images. The Automatic Clustering Engine function [QTC IMPACT User Manual, 2004], was used for splitting acoustic signals into a final number of classes that fits with the optimal split level suggested by the statistical parameters.

Sediment samples were analyzed following the procedure described by Wienberg and Bartholomä (2005) and classified using the GRADISTAT statistics package [Blott and Pye 2001]. The PAST software (Hammer 2001) was used for statistical analysis (Non-metric MDS and Cluster analysis). All the data were finally loaded in ArcGIS v9.2 for interpretation. 


\section{RESULTS}

\section{Sedimentary data}

Due to the strong tidal currents acting in the area, sampling positions were shifted with respect to the planned locations, the average distance between replications being $20 \mathrm{~m}$ (Table 1a). Station $\mathrm{C}$ shows the highest positioning error (average distance between replications: $32 \mathrm{~m}$ ).

Sediments grain sizes range from coarse silt to very fine gravel (Table $1 \mathrm{~b}$ ), the main part (75\%) falling into the sand fraction. Replications show significant difference in sediment composition: Station A presents the lowest variability, all the replications being dominated by sand. Station $C$, on the contrary, is characterized by the highest variability in composition, with the replication JSA04 muddybased $(47.6 \%)$, J SA09 totally sandy $(91.8 \%)$ and J SA019 and J SA022 gravelly dominated $(55.4 \%$ and $47.7 \%$, respectively). Replications JSA02 and JSA14 (Station D) are the closest ones of the survey (distance $=2 \mathrm{~m}$ ). Nevertheless, J SA02 presents a high content of mud $(75.4 \%)$ and J SA14 is dominated by sand $(60.1 \%)$. Similar results for Station E, where JSA10 is characterized by a $75.7 \%$ of mud, while J SA15 composition is mainly given by the sand fraction (76.6\%), albeit they are only $7 \mathrm{~m}$ far.

\begin{tabular}{|c|c|c|c|c|c|c|c|c|c|c|c|c|}
\hline \multirow{2}{*}{\multicolumn{2}{|c|}{ Station A }} & \multirow{2}{*}{\multicolumn{2}{|c|}{ (av.dist $=15 \mathrm{~m})$}} & \multirow{2}{*}{\multicolumn{2}{|c|}{ Station B }} & \multirow{2}{*}{\multicolumn{2}{|c|}{ (av.dist= 20m) }} & Sample & Gravel $\%$ & Sand \% & Mud $\%$ & \\
\hline & & & & & & & & JSA05 & 3.0 & 64.7 & 32.3 & \multirow[b]{3}{*}{ A } \\
\hline & JSA07 & JSA18 & JSA23 & & JSA08 & JSA17 & JSA25 & JSA07 & 3.9 & 69.6 & 26.5 & \\
\hline JSA05 & 17 & 17 & 20 & JSA06 & 28 & 18 & 28 & JSA18 & 0.0 & 71.6 & 28.4 & \\
\hline JSA07 & & 14 & 18 & JSA08 & & 16 & 18 & JSA23 & 13.6 & 57.9 & 28.5 & \\
\hline \multirow[t]{2}{*}{ JSA18 } & & & 3 & JSA17 & & & 10 & JSA06 & 32.5 & 59.7 & 7.7 & \\
\hline & & & & & & & & JSA08 & 58.7 & 30.0 & 11.2 & \\
\hline \multicolumn{2}{|c|}{ Station C } & \multicolumn{2}{|c|}{ (av.dist $=32 \mathrm{~m}$ ) } & \multicolumn{2}{|c|}{ Station D } & \multicolumn{2}{|c|}{ (av. dist $=21 \mathrm{~m}$ ) } & JSA17 & 17.5 & 67.2 & 15.3 & B \\
\hline & JSA09 & JSA19 & JSA22 & & JSA12 & JSA14 & JSA21 & JSA25 & 63.9 & 21.9 & 14.1 & \\
\hline JSA04 & 37 & 39 & 50 & JSA02 & 38 & 2 & 13 & JSA04 & 19.2 & 33.3 & 47.6 & \\
\hline JSA09 & & 19 & 20 & JSA12 & & 36 & 26 & JSA09 & 0.0 & 91.8 & 8.2 & \\
\hline \multirow{2}{*}{\multicolumn{2}{|c|}{ JSA19 }} & & 25 & JSA14 & & & 11 & JSA19 & 55.4 & 34.2 & 10.4 & C \\
\hline & & & & & & & & JSA22 & 47.7 & 45.5 & 6.8 & \\
\hline \multicolumn{2}{|c|}{ Station E } & \multicolumn{2}{|c|}{ (av. dist $=13 \mathrm{~m}$ ) } & \multicolumn{2}{|c|}{ Station F } & \multicolumn{2}{|c|}{ (av. dist $=16 \mathrm{~m}$ ) } & JSA02 & 0.0 & 24.6 & 75.4 & \\
\hline & JSA10 & JSA15 & JSA24 & & JSA11 & JSA13 & JSA20 & JSA12 & 4.2 & 89.0 & 6.8 & \\
\hline JSA03 & 4 & 11 & 23 & JSA01 & 14 & 13 & 13 & JSA14 & 1.6 & 60.1 & 38.4 & D \\
\hline JSA10 & & 7 & 19 & JSA11 & & 5 & 27 & JSA21 & 0.9 & 66.3 & 32.8 & \\
\hline \multirow{2}{*}{\multicolumn{2}{|c|}{ JSA15 }} & & 13 & JSA13 & & & 25 & JSA03 & 0.0 & 25.7 & 74.3 & \\
\hline & & & & & & & & JSA10 & 0.0 & 24.3 & 75.7 & \\
\hline \multirow{6}{*}{\multicolumn{8}{|c|}{$\begin{array}{l}\text { Table 1a (left) and } \mathbf{1 b} \text { (right). 1a: average distance between } \\
\text { replications. 1b: sediment grain size analysis, expressed as } \\
\text { dry weight percent on total sediment. }\end{array}$}} & JSA15 & 11.7 & 76.6 & 11.7 & $\mathrm{E}$ \\
\hline & & & & & & & & JSA24 & 0.0 & 95.4 & 4.6 & \\
\hline & & & & & & & & JSA01 & 24.1 & 52.8 & 23.0 & \\
\hline & & & & & & & & JSA11 & 16.9 & 64.3 & 18.8 & \\
\hline & & & & & & & & JSA13 & 2.1 & 62.3 & 35.6 & $\mathrm{~F}$ \\
\hline & & & & & & & & JSA2O & 13.1 & 84.0 & 2.9 & \\
\hline
\end{tabular}

The results of statistical analysis confirm that there is no significant correlation between sediment similarity and sampling closeness. In particular, only replications from Station A tend to group, while the already mentioned replications from Station $D$ and $E$ show low similarity values, in spite of their closeness (Figure 3a).

\section{Acoustic data}

The whole area is characterized by distinctive topographic features, mainly related to dredging operations. From West to East, 6 main morphological domains can be mapped (Figure 2):

- W: a wide area dominated by dredging marks related to the Jade-Weser Port construction phase;

- $\quad$ H: western high (min. depth: $14.4 \mathrm{~m}$ ), without dredging scours;

- $\quad$ P: western pit ( max. depth: $26.4 \mathrm{~m}$ ), without dredging scours;

- $\quad \mathrm{N}$ : old navigation channel, marked by regularly spaced and shaped dredging scours, elongated and parallels to the navigation channel;

B: large bedform fields, mainly aside the old navigation channel; 
- $\quad$ E: a wide domain characterized by the absence of dredging marks and by the presence of diffuse short-wave bedforms. It is the less disturbed area.

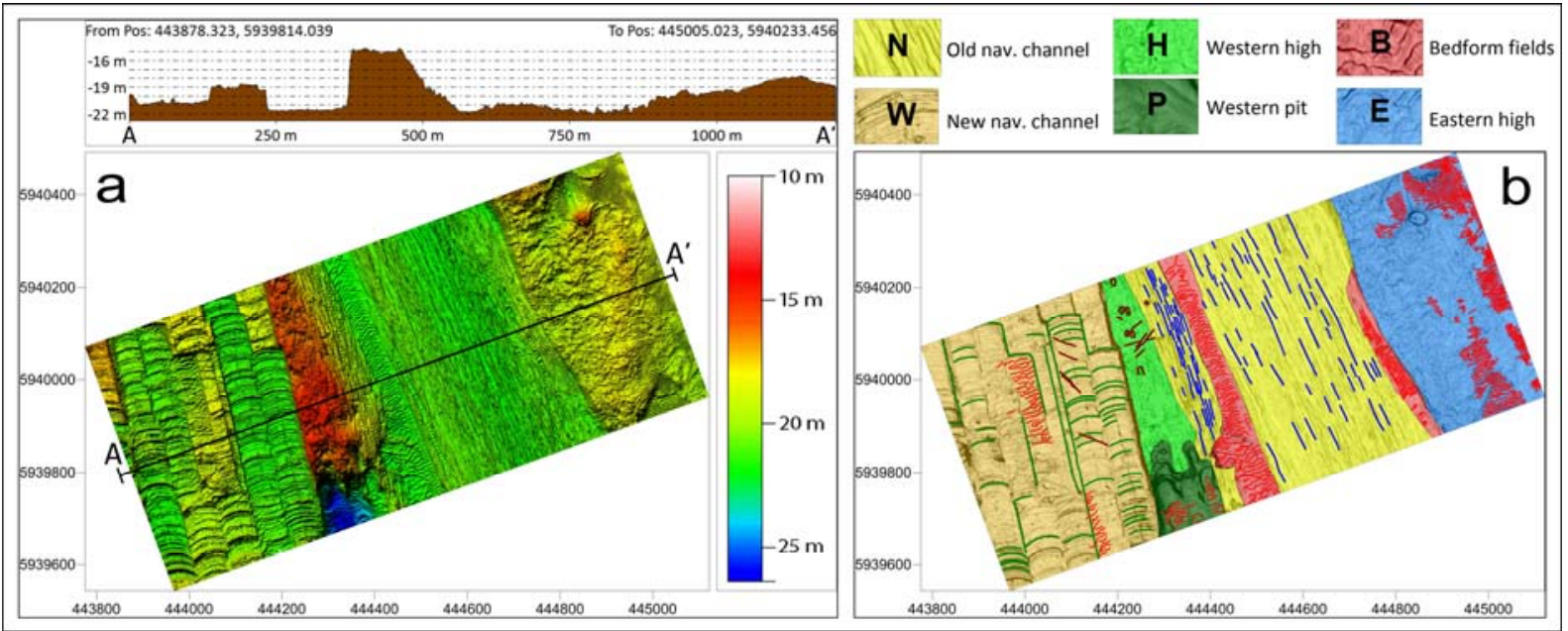

Figure 2: DTM of the research area (a) and main morphological domains (b).

The SBES final classification (optimal splitting level: 4) shows a patchy distribution of acoustic classes all over the area, with a dominance of the turquoise-colored class $(42.2 \%)$ and brown-colored class $(32.0 \%)$, which do not correspond to any morphological domain (Figure $3 \mathrm{~b}$ ). The pink-colored class $(6.1 \%)$ is the only one focused around specific regions ( $\mathrm{H}$ and $\mathrm{P}$ domains), while the blue-colored one $(19.7 \%)$ is scattered all over the area, but scarcely represented in the same domains. All considering the extreme variability of sediment composition and distribution, the error in positioning and the patchiness of the acoustic classification, it is not possible to clearly correlate acoustic classes and sedimentary data.

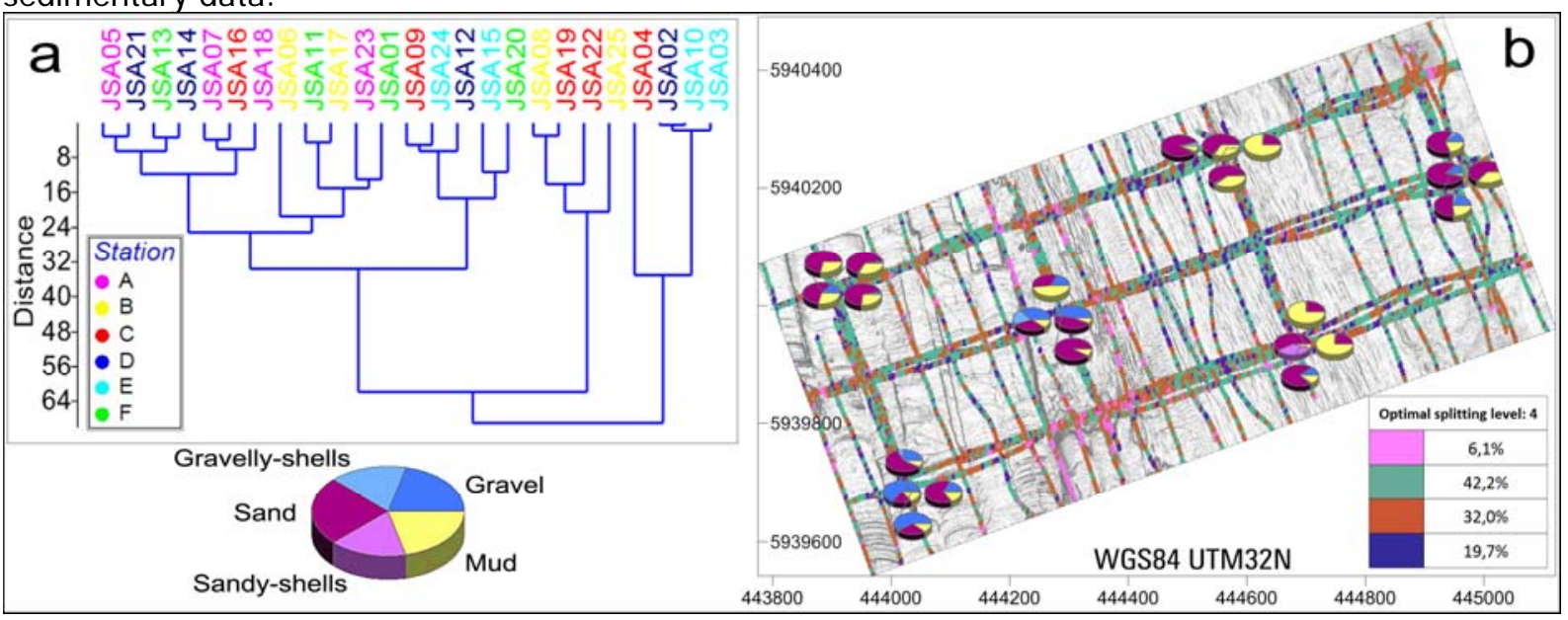

Figure 3: Clustering analysis, Euclidean similarity measure (a). SBES acoustic classification (b), overlaid by the sediment data.

The grey-colored class prevails $(69,2 \%)$ in the MBES acoustic classification (optimal split level: 5 . Figure $4 \mathrm{a})$, marking both the western (W) and eastern (E) regions, including the $B$ areas and with the exception of the $\mathrm{H}$ and $\mathrm{P}$ domains. 2 specific classes (light and dark blue-colored ones, $14.2 \%$ and $8.1 \%$, respectively) cover the $N$ morphological domain, where the green-colored class $(2.8 \%)$ is also present. Thus, a correlation between main seabed features and acoustic classification is clear. The turquoise-colored class (5.7\%) is spread all over the area. There is no correspondence between acoustic classes and sedimentary data: in fact, every acoustic class can be related to different sediment types and the same sedimentary group corresponds to more than one acoustic class. 
The general pattern of the SSS classification (optimal split level: 4) follows the main morphological divisions (Figure 4b), with the green-colored class (36.3\%) fitting the $\mathrm{N}$ area and the remaining classes distributed both in the western and eastern regions. The $\mathrm{W}$ domain seems to be equally represented by both the orange- $(30.7 \%)$ and the violet-colored $(24.0 \%)$ classes, while the $\mathrm{E}$ topographic area is mainly covered by the orange-colored class. The blue-colored class characterizes the slope between the $\mathrm{H}-\mathrm{P}$ and $\mathrm{N}$ regions.

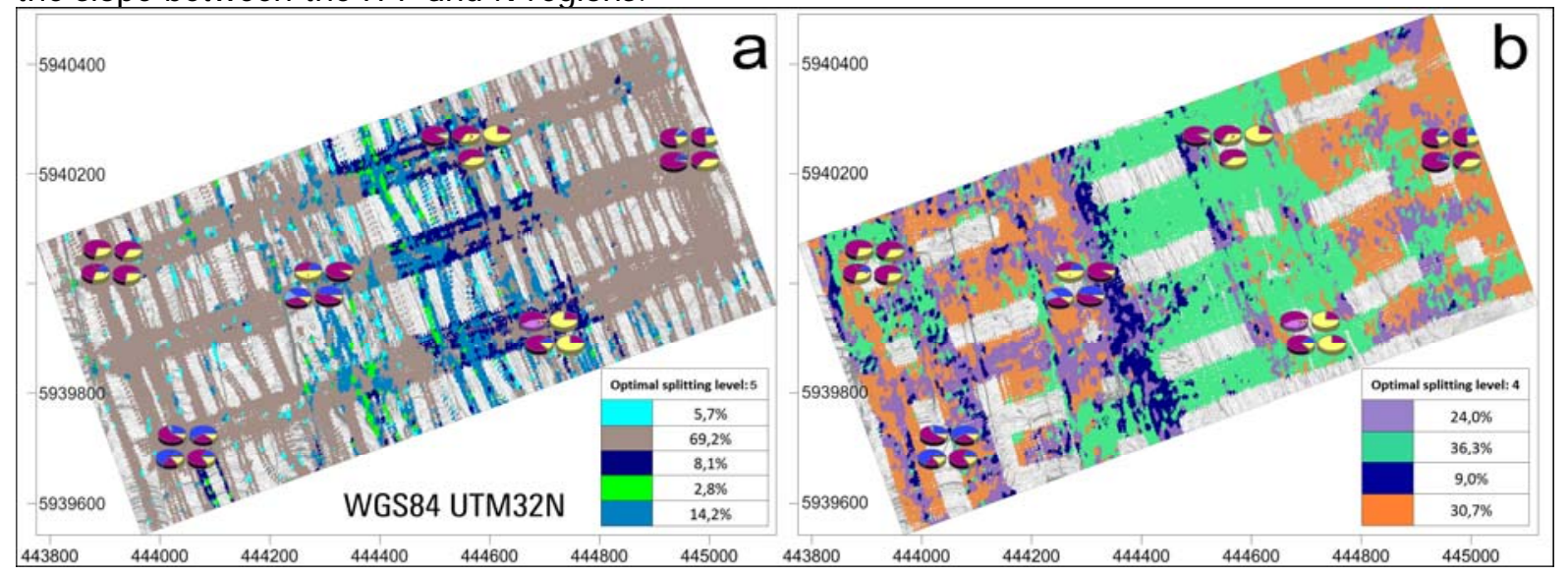

Figure 4: MBES acoustic classification (a) and SSS acoustic classification (b).

The same catalogue of 4 classes was used for classifying separately the 4 north-south and the 3 eastwest SSS lines, showing significant differences. In particular, the area corresponding to the old navigation channel presents a homogeneous dominance of the turquoise-colored class in the eastwest transects, whereas the same region shows a distinctive multi-class pattern parallel to the dredging marks in the north-south classification.

As for the MBES classification, the ground truthing process does not show any univocal correspondence between sediments and the SSS acoustic classes.

\section{DISCUSSION AND CONCLUSIONS}

Errors are always associated with sampling positioning. The mismatch between the planned and the sampled location can be negligible in homogeneous environment, giving a reliable classification. Punctual information can then be used for validating acoustic data even when the two sources does not perfectly overlap, assuming that the information inferred for a given position can be consistently extended to a certain neighborhood. This is not true for highly heterogeneous environments; in fact, repeated sampling clearly demonstrates that:

- $\quad$ Replications show significant differences in sediment composition;

- $\quad$ There is not clear relationship between positioning and similarity;

- $\quad$ Less disturbed areas (e.g. station F) present the same variability of directed multi-impacted ones (e.g., Station A), therefore there is no link between anthropic disturbance and heterogeneity.

The results show that repeated sampling is a must in such complex environments.

SBES classification reveals a highly heterogeneous seabed texture with no clear dominant pattern, thus being likely controlled by the distinctive patchiness in sediment distribution (=sediment roughness). Nevertheless, the extreme variability of sediment composition does not allow any interpolation: only the samples located exactly along the acoustic line could be theoretically used for ground-truthing, resulting in a scarcely sufficient amount of information. In conclusion, SBES classification is ruled by sediment patchiness, but the final classification can hardly be translated into sedimentological information.

On the contrary, swath-based systems (MBES and SSS) seem to be largely dependent on seabed topography for their classification, with acoustic classes that match the general division in morphological domains (= topographic roughness). MBES does not allow the distinction between W 
and $E$ regions, although they represent end members of highly disturbed and less disturbed environments. SSS classification not only stresses the different topographic domains, but also distinguishes between $\mathrm{W}$ and $\mathrm{E}$ regions. The angle between the acoustic lines and the seabed features is crucial for the final acoustic classification. In fact, regularly shaped and spaced features, like dredging marks, could lead to significantly different results.

In conclusion, mapping highly heterogeneous and disturbed environments is a crucial challenge for monitoring and protecting these extremely sensitive areas. Hydro-acoustic systems coupled with repeated sampling allow running this process in high resolution, but the resulting classification is mainly ruled by the sediment roughness for SBES systems and by topographic micro-roughness for swath-based devices. In any case, the resulting classes can only partially be linked to a proper sedimentological meaning.

\section{CONTACT DETAILS}

Ruggero Maria CAPPERUCCI

Marine Research Department, Senckenberg am Meer

Südstrand 40, 26382 Wilhelmshaven, Germany

Tel.: +49 (0)4421 9475212

Email: Ruggero.Capperucci@senckenberg.de

\section{REFERENCES}

Blott, S.J., and K. Pye 2001. "GRADISTAT: a grain size distribution and statistics package for the analysis of unconsolidated sediments." Earth Surface Processes and Landforms 26: 1237-1248.

Brown, C.J., S.J. Smith, P. Lawton and J.T. Anderson 2011. "Benthic habitat mapping: A review of progress towards improved understanding of the spatial ecology of the seafloor using acoustic techniques." Estuarine, Coastal and Shelf Science 92: 502-520.

Cutter J r., G.R., , Y. Rzhanov, and L.A. Mayer 2003. "Automated segmentation of seafloor bathymetry from multibeam echosounder data using local Fourier histogram texture features." Journal of Experimental Marine Biology and Ecology 285-286: 355- 370.

Hammer, Ø., D.A.T. Harper, and P.D. Ryan 2001. "PAST: Paleontological Statistics Software Package for Education and Data Analysis." Palaeontologia Electronica 4: 9pp.

Hayes, M.O. 1975. "Morphology of sand accumulations in estuaries: an introduction to the symposium." In Estuarine Research, vol. 2, ed. L.E. Cronin, 3-22. New York: Academic Press.

Herlyn, M., and G. Millat 2000. "Decline of the intertidal blue mussel (Mytilus edulis) stock at the coast of Lower Saxony (Wadden Sea) and influence of mussel fishery on the development of young mussel beds." Hydrobiologia 426: 203-210.

Kahlfeld, A., and H. Schüttrumpf 2006. "Untrim modelling for investigating environmental impacts caused by a new container terminal within the Jade-Weser Estuary, German Bight." In: Proceedings of the 7th International Conference on HydroScience and Engineering, Philadelphia, USA, September 10-13, 2006, 13pp..

OSPAR 2004. "Environmental Impacts to marine species and habitats of dredging for navigational purposes." OSPAR Commission, Biodiversity Series : 22pp.

OSPAR 2008. "Assessment of the environmental impact of land reclamation", OSPAR Commission, Biodiversity Series, Publication number 368/2008 : 37pp.

QTC IMPACT User Manual, 2004. QTC IMPACT Acoustic Seabed Classification.User Manual, Version 3.40. Quester Tangent Corporation, Marine Technology Centre, Sidney, B.C., Canada, 153 p.

van der Veen, H.H., and S.J.M.H. Hulscher 2008. "Effect of large scale human activities on the North Sea seabed." In Marine and River Dune Dynamics, ed. Parsons, D., Garlan, T. and Best, J., 307-314.

Wienberg, C., and A. Bartholomä 2005. "Acoustic seabed classification of a coastal environment (outer Weser Estuary, German Bight) - a new approach to monitor dredging and dredge spoil disposal.", Journal of Continental Shelf Research 25: 1143-1156.

Winter, C., and A. Bartholomä 2006. "Coastal dynamics and human impact: south-eastern North Sea, an overview." Geo-Marine Letters 26: 121-124. 